\title{
A pavement-watering thermal model for SOLENE-microclimat: development and evaluation
}

\author{
AZAM Marie-Hélène ${ }^{\mathrm{a}, \mathrm{c}, 1, *}$, BERNARD Jérémy ${ }^{\mathrm{b}}$, MORILLE Benjamin ${ }^{\mathrm{a}}$, \\ MUSY Marjorie ${ }^{a, c, 1}$, ANDRIEU Hervé ${ }^{a, d}$ \\ ${ }^{a}$ Institut de Recherche en Sciences et Techniques de la Ville, FR CNRS 2488, F-44000 \\ Nantes, France \\ ${ }^{b}$ UMR CNRS 6285, Lab-STICC, F-56000 Vannes, France \\ ${ }^{c}$ Cerema, F-44000 Nantes, France \\ ${ }^{d}$ Institut français des sciences et technologies des transports, de l'aménagement et des \\ réseaux, F-44000 Bouguenais, France \\ ${ }^{e}$ UMR CNRS 6183, GeM, Université de Nantes, F-44000 Nantes, France
}

\begin{abstract}
In a dense urban area, pavement watering could be a solution to mitigate the Urban Heat Island. So far, mainly experimental studies have been used to evaluate watering techniques. In this study, a soil model dedicated to pavement watering has been developed within the urban climate model SOLENE-Microclimat. This watering model is presented and evaluated via a measurement campaign performed on an asphalt car park during warm days. The measurement campaign reveals that the surface cooling is mainly due to evaporation (80\%). However, under warm conditions, the heat flux exchanged between the runoff water and the surface should also be modelled. Indeed, watering events are modelled through a runoff convective heat flux and a latent heat flux. The mean daily RMSE between estimated and observed surface temperature is $1.04^{\circ} \mathrm{C}, 0.86^{\circ} \mathrm{C}, 0.66^{\circ} \mathrm{C}, 0.35^{\circ} \mathrm{C}$ and $0.21^{\circ} \mathrm{C}$
\end{abstract}

\footnotetext{
*Corresponding author. E-mail address: marie-helene.azam@cerema.fr Address: Cerema, 9 rue René Viviani, 44000 Nantes, France
} 
respectively at the surface, $5 \mathrm{~cm}-, 10 \mathrm{~cm}-, 34 \mathrm{~cm}-$ and $50 \mathrm{~cm}$-depths.

Keywords: Pavement-watering, Soil surface temperature,

SOLENE-Microclimat, Urban Heat Island, Climate Adaptation 


\section{Highlights}

- A watering model is proposed to assess the impact of pavement watering techniques.

- Waterings are modelled by a runoff convective heat flux and a latent heat flux.

- Under warm conditions both fluxes should be modelled to reproduce the dynamics.

- Temperature observed at several depths are used to evaluate the computed temperature. 


\section{Contents}

1 Introduction 5

1.1 Watering techniques .............. 5

1.2 Pavement watering in microclimatic models . . . . . . . . 7

$\begin{array}{llr}2 & \text { Method } & 9\end{array}$

2.1 SOLENE-microclimat soil model . . . . . . . . . . . 9

2.2 Proposed watering model . . . . . . . . . . . . . . . 11

2.2.1 Energy balance at the surface . . . . . . . . . 11

2.2.2 Runoff convective heat flux . . . . . . . . . . . . 13

2.2.3 Latent heat flux between water and atmosphere . . . 14

2.2.4 Heat fluxes dynamic . . . . . . . . . . . . . . . 17

$\begin{array}{llr}3 & \text { Model assessment } & 20\end{array}$

3.1 Case study. . . . . . . . . . . . . . . 20

3.1.1 Studied area and measurement description . . . . . . 20

3.1.2 Description of the watering events . . . . . . . . 21

3.1.3 Validation of the model assumptions . . . . . . . 23

3.1.4 Water budget ................ 25

3.2 Comparison between simulation and measurement . . . . . . . 26

3.2.1 Model setup . . . . . . . . . . . . . 27

3.2.2 Watering model evaluation on ROSURE data . . . . . 30

3.2.3 Model sensitivity to the discretization . . . . . . . 33

4 Conclusion $\quad 36$ 
1

2 3

\section{Introduction}

The Intergovernmental Panel on Climate Change (IPCC) assessed that heatwaves will be more frequent and more intense during the $21^{\text {st }}$ century than during the $20^{\text {th }}$ century. The last major European heatwaves led to approximately 70,000 excess deaths across the continent (Robine et al., 2008 [1]). The urban heat island (UHI) effect exacerbates the consequences of such climatic event on human health, as confirmed by Laaidi et al. (2012 [2]) and Conti et al. (2005 [3]) who showed a clear relationship between UHI and mortality in Paris and in Italian cities respectively. Reducing the UHI is then a major challenge addressed to the scientific community. Several countermeasures are currently investigated in all regions of the world and under different climates. Santamouris et al. (2016 [4]) reviewed the performances of the most common UHI mitigation technologies: building material albedo, vegetation, water. He concludes that UHI may be partly or fully annihilated using a combination of all technologies but that there is a need to improve the performances of each of them. The present article focuses on the pavement watering solutions. Regardless the technique used to spread the water (cleaning trucks - Hendel et al., 2015 [5] - or sprinklers set in the street structure - Himeno et al., 2010 [6]), the correct modelling of the physical phenomenon induced by this technique and their interaction with local climate will help to improve its performances.

\subsection{Watering techniques}

In very dense urban areas, the UHI may be mitigated by spreading water over pavements. The evaporation of the water in the air and the heat flux 
exchanged between the water and the ground contribute to cool both the surface and the air temperature. It also induces an increase of the air humidity. Yang and Zhao (2015 [7]) investigated the effect of different surfaces (water ponds, low vegetation, asphalt) on the air temperature and humidity through an experimental work realised under hot climate conditions. They measured humidity and air temperature gradients over the different studied surfaces. If they can measure high differences over the specific humidity variable close to the ground, these differences strongly decrease with the height. At $1.2 \mathrm{~m}$ high, the profiles are similar, even with low air velocities. As a result, impact of watering on air humidity should not alter the effect obtained thanks to the lower surface temperature.

Daniel et al.(2016 [8]), confirmed that watering mainly limits the warming of the urban surface, reducing their infrared emissions. They found that watering techniques have a positive impact on human comfort. The used index comfort (UTCI) may be increased by the humidity but it is also decreased by the air temperature and mainly by the surface temperature. Finally Broadbent at al. (2017 [9]) showed that the average increase of vapour pressure did not have a negative influence on comfort under very hot and dry climate (South Australia during summer).

Under warm conditions, these processes offer a quick response while the water is spread over the surface. However, evaporation is constrained by the pavement water-holding capacity (which depends on the surface roughness). Below a certain volume of water spread, all the water is stored in the surface porosity and can evapourate. Above a threshold proper to the surface char- 
acteristics, the holding capacity of the surface is over-passed and the water excess runs off toward sewers.

Watering techniques have been mainly studied through experimental works (Hendel et al., 2015 [5], Himeno et al., 2010 [6]) which confirm the positive impact of watering techniques. Himeno et al., (2010 [6]) found that in the case of hot weather (above $30^{\circ} \mathrm{C}$ ), pavement watering can reduce the air temperature by $2^{\circ} \mathrm{C}$ in the morning and $4^{\circ} \mathrm{C}$ in the afternoon. Hendel et al. (2015 [10]) worked on the optimisation of those waterings, minimising the total amount of water spread, maximising the evaporation. With a watering rate of 0.31 to $0.41 \mathrm{~L} / \mathrm{m}^{2} / \mathrm{h}$ every 30 minutes, the surface temperature could be reduced by $4^{\circ} \mathrm{C}$ in the morning and $13^{\circ} \mathrm{C}$ in the afternoon. According to Broadbent et al. (2017 [9]), the performance assessment of watering techniques during heatwave conditions at the micro-scale has rarely been modelled. Daniel et al. (2016 [8]), Grossman-Clarke et al. (2010 [11]) and Boadbent et al. (2017 [9]) evaluated the mitigation potential of these techniques at the meso-scale.

\subsection{Pavement watering in microclimatic models}

In the literature, most of the models used to simulate the urban surface energy balance, calculate the latent heat flux induced by the vegetation (Grimmond et al., 2010 [12]). However, these models are not appropriate for pavement watering application since they do not consider the heat flux exchanged between the surface and the runoff water.

The Town Energy Balance (TEB) model (Masson, 2000 [13]) is one of the few urban climate models that is able to simulate pavement watering events (Daniel et al., 2016 [8], Broadbent et al. 2017 [9]) at meso-scale. It 
distinguishes the evapotranspiration from the evaporation over impervious surfaces. In the case of impervious surface, the following processes are modelled: interception, evaporation of the available water and surface runoff. For each surface, a water reservoir is set according to the water holding capacity of the pavement and its content is updated at each time step. It is filled during a watering event and emptied by the evaporation. When the maximum capacity of the reservoir is reached, the excess is transferred to the sewer. By default, the pavement considered in the model is a road and its storage capacity is set at $1 \mathrm{~mm}$ (Daniel et al., 2016 [8]). However, this parameter is a variable of the model and then may be set to a different value (see section $3.2 \cdot 1)$.

microclimate tools (Grimmond et al., 2010 [12]), waterings over impervious surface could not be model.

The watering model is elaborated based on a review of the literature and evaluated on an open asphalt parking lot, chosen to avoid interference with other surfaces thermal behaviour, like solar radiation diffusion and reflection as well as long-wave emission from the surrounding vertical surfaces (building 
facades). In these conditions, we can isolate the watering model from the other SOLENE-microclimat model pieces and assess it properly. This article is the second step of a complete evaluation of SOLENE-Microclimat soil model. Indeed in a previous article (Azam et al., 2017 [17]), the soil model has been assessed under same conditions.

The model is presented in section 2. After a review of the different methods used to calculate each heat flux, the model equations are developed and the algorithm is sum-up in a flow-chart (section 2.2.4). Section 3 deals with the model evaluation. The case study is first presented (section 3.1). Based on those results assumptions previously made are verified. Results of the model are compared to the observed temperature and heat flux (section 3.2). The model is evaluated on surface temperature and latent heat flux. Finally, the sensitivity of the model to the soil model node distribution is studied.

\section{Method}

The proposed watering pavement model will be an additional model pieces to the soil model used in SOLENE-microclimat. The SOLENE-microclimat original soil model is briefly presented in section 2.1 but further details are available in Azam et al.(2017 [17]). Then the proposed watering model is presented in section 2.2 .

\subsection{SOLENE-microclimat soil model}

SOLENE-microclimat soil model is designed for an impervious surface like a pavement coating. Only heat transfer is therefore taken into account, 
the moisture transfer being neglected. The soil model is defined as a onedimensional soil column (for each soil facet) where each layer has its own characteristics (Figure 1)

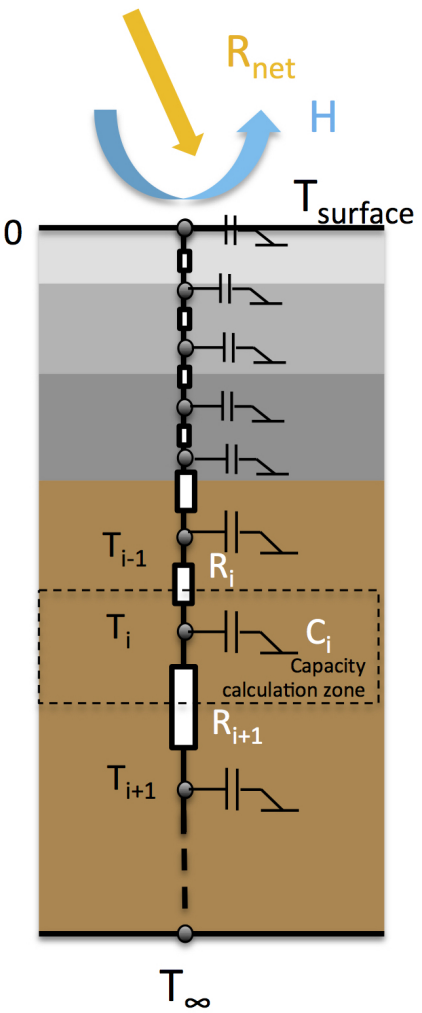

Figure 1: Schematic representation of the soil model: representation of the node distribution, heat resistances and capacities, description of a common cross-section of urban soil column with diffusive materials layers in shade of grey and underneath natural soil in brown (Azam et al., 2017 [17])

The problem is solved by a finite difference method using an electrical analogy. A mesh with one node per centimetre is used. At the surface, the upper boundary condition is defined by the surface energy balance detail after. The temperature at $0.75 \mathrm{~m}$ is set with the measured temperature signal 
at this depth. A more detailed description of the SOLENE-microclimat soil model can be found in Azam et al. (2017 [17]).

\subsection{Proposed watering model}

\subsubsection{Energy balance at the surface}

The net radiative heat flux density $\left(R_{n e t}\right)$ that reaches a dry pavement is turned into two fluxes: a conductive heat flux density $\left(Q_{\text {cond }}\right)$ and a sensible heat flux density $(H)$. Equation (1) is used to define the upper boundary condition of the soil model.

$$
R_{\text {net }}=Q_{\text {cond }}+H
$$

$R_{\text {net }}$ : net radiative heat flux density $\left[\mathrm{W} / \mathrm{m}^{2}\right]$

$Q_{\text {cond }}$ : conductive heat flux density $\left[\mathrm{W} / \mathrm{m}^{2}\right]$

$H$ : sensible heat flux density $\left[W / m^{2}\right]$

A watering event alters this energy balance. The water spread on a surface follows one of the following path: 1 / infiltration in the soil, 2/run-off toward the neighbouring surface or to the water network and 3/evaporation. Each path implies a modification of the surface energy balance:

- a part of the water infiltrates the soil: the thermal properties of the soil can vary with the water content and a heat flux is exchanged between the water and the soil layers.

- a part of the water runs-off: a heat flux is exchanged between the water and the surface. 
- a part of the water evapourates: a latent heat flux is exchanged between the water and the atmosphere.

Pavement surfaces can be modelled as semi-impervious surfaces (Dupont et al., 2006 [18]) or as impervious surfaces (Herb et al., 2008 [19]; Hendel et al., 2015 [10]). In the first case, downward infiltration should be taken into account whereas the proportion of infiltrated water in the second case is supposed negligible compared with the one that runs-off or evapourates. As the model is only dedicate to paved surface (i.e. asphalt), we will consider our surface as impervious. Overall the watering model needs to take into account two fluxes initially not considered in Equation (1): a runoff convective heat flux density exchanged between the surface and the water $\left(Q_{\text {wat-pav }}\right)$ and a latent heat flux density $(L E)$ between the water and the atmosphere (Herb et al., 2008 [19]; Hendel et al., 2015 [10]). The resulting surface energy balance is then given by Equation (2). The calculation of these fluxes is further described in the following sections.

$$
R_{\text {net }}=Q_{\text {cond }}+H+Q_{\text {wat-pav }}+L E
$$

$L E$ : latent heat flux density exchanged between the water and the atmosphere $\left[W / m^{2}\right]$

$Q_{\text {wat-pav }}$ : runoff convective heat flux density exchanged between the surface and the water $\left[W / m^{2}\right]$ 
179

\subsubsection{Runoff convective heat flux}

Herb et al. (2008 [19]) evaluated the convective heat flux exchanged between the surface and the water from the energy absorbed by the water and released by the soil. With the same idea, in our model, this runoff convective flux is calculated from the energy absorbed by the water (Equation (3)). The temperature variation is calculated between the soil surface temperature at the time step $t$ and the temperature of the water before it reaches the ground. Herb et al. (2008 [19]) modelled rain events, the water temperature is then supposed equal to the dew-point temperature. In our case, the water spread is assumed equal to the pipe network temperature.

$$
Q_{w a t-p a v}=\frac{\rho_{w} \cdot C_{p, w} \cdot h_{w, s p r}}{\Delta t}\left(T_{s u r f}(t)-T_{w}\right)
$$

$h_{w, s p r}$ : water height evenly sprinkled on the surface $[m]$

$T_{w}$ : temperature of the water $[K]$

$\rho_{w}:$ water density $\left[\mathrm{kg} / \mathrm{m}^{3}\right]$

$C_{p, w}:$ water specific heat $[\mathrm{J} / \mathrm{kg} / \mathrm{K}]$

$T_{\text {surf }}(t)$ : surface temperature at the time step $\mathrm{t}[\mathrm{J} / \mathrm{kg} / \mathrm{K}]$

Herb et al. (2008 [19]) made the assumption that the runoff water reaches the ground temperature instantly by conduction. The same assumption will be made in the model and verified from the measurements analysis in section 3.1.3. 


\subsubsection{Latent heat flux between water and atmosphere}

The evaporation is driven by two factors: the amount of heat available at the free surface and the vapour pressure gradient in the near air. These factors depend on meteorological variables including radiation, air pressure, wind speed, temperature but also on other variables like the surface roughness. Various methods have been developed to evaluate the evaporation rate. Xu and Singh (1997 [20]; 2001 [21]) proposed to sort them into 6 classes: (i) water budget, (ii) mass-transfer or aerodynamic based method, (iii) energy budget method or combination (e.g. Penman, 1948), (iv) radiation, (v) temperature based method, (vi) empirical methods. The empirical methods are applicable only for specific cases with a specific range of variables, which limits their application conditions. The radiation and the temperature based methods are specific empirical methods. They only use one meteorological variables as inputs (either radiation term, either temperature) to estimate the evaporation whereas it is influenced by numerous other important factors (i.e. relative humidity, wind speed, etc). Singh and Xu (1997 [20]) observed that water budget method is based on a simple theoretical basis but that they rarely produce reliable results. Energy budget method and combination method reproduce well the physics but they need many meteorological input data. Mass-transfer method is a good compromise since the accuracy is reasonable (Singh and Xu, 1997 [20]) for less meteorological input data needed. It is the most commonly used method to develop soil models (Asaeda and Ca, 1993 [22]; Qin et al., 2002 [23]; Saito and Simunek, 2009 [24]; Herb et al.,2008 [19], Best, 1998 [25]). It is also used in our model.

The mass-transfer method is based on the Dalton Equation, described by 
215

Equation (4).

$$
L E=C \cdot\left[q_{\text {sat }}\left(T_{\text {surf }}\right)-q_{a}\left(T_{\text {air }}\right)\right]
$$

216

217

$C$ : the aerodynamic conductance

$q_{\text {sat }}\left(T_{\text {surf }}\right)-q_{a}\left(T_{\text {air }}\right)$ : the vapour pressure gradient between the actual air vapour pressure and the saturation vapour pressure at the surface temperature

(2)

The aerodynamic conductance is generally modelled using a combination of the air density $\rho_{\text {air }}$, the latent heat $L$, and a heat transfer resistance $R$ (Equation (5)). Several methods can be used to calculate this last parameter.

The heat transfer resistance can be calculated as a function of the convective heat transfer coefficient $h_{c}$ (Mihalakakou et al. 1997 [26]; Herb et al., 2008 [19]); or as a combination of a surface and an aerodynamic resistance calculated using standard Monin-Obukhov similarity theory (Best, 1998 [25]; Asaeda and Ca, 1993 [22]; Qin et al., 2002 [23]; Saito and Simunek, 2009 $[24])$.

$$
C=\rho_{\text {air }} \cdot \frac{L}{R}
$$

$\rho_{\text {air }}:$ air density $\left[\mathrm{kg} / \mathrm{m}^{3}\right]$

$L$ : the latent heat $[\mathrm{J} / \mathrm{kg}]$

$R$ : heat transfer resistance's $[s / m]$ 
235

In our model, the heat transfer resistance is a function of the convective heat transfer coefficient (Equation (6)). It is calculated from the correlation method with a characteristic length of 1m (for more detail see Azam et al., 2017 [17]). This method considers forced, mixed and natural convective heat fluxes.

$$
R=\rho_{\text {air }} \cdot \frac{C_{p, a i r}}{h_{c}}
$$

$C_{p, a i r}:$ air specific heat $[\mathrm{J} / \mathrm{kg} / \mathrm{K}]$

$h_{c}$ : the convective heat transfer coefficient $\left[W / m^{2} / K\right]$

As the surface is impervious, the latent heat flux is only calculated when some water is present on the surface. This heat flux depends on the air characteristics (temperature, pressure, humidity and wind speed). The vapour pressure gradient is calculated between the air at a certain height and the saturated air very close to the water surface. The hypothesis is made that the saturated air very close to the water surface is at the same temperature than the water surface. The vapour pressure is calculated according to the Magnus-Tetens formulas (Alduchov and Eskridge, 1996 [27]) described by Equations (7), (8) and (9).

$$
\begin{gathered}
q_{\text {sat }}=0.662 \frac{V P_{\text {sat }}}{101325-0.378 V P_{\text {sat }}} \\
q_{a}=0.662 \frac{V P_{\text {sat }} \frac{R H}{100}}{101325-0.378 V P_{\text {sat }} \frac{R H}{100}}
\end{gathered}
$$




$$
V P_{\text {sat }}=611.2 \exp \left(\frac{17.67 T}{243.5+T}\right)
$$

$V P_{\text {sat }}:$ saturated vapour pressure $[\mathrm{Pa}]$

RH: Relative Humidity [\%]

\subsubsection{Heat fluxes dynamic}

The Surface Energy Balance (hereafter denoted SEB) method is presented in Figure 2. For each time step, the equivalent height of water that is evenly sprinkled on the surface is noted $h_{w, s p r}$. The total height of water is noted $h_{w, t o t}$. Then three cases are considered:

- $h_{w, t o t}$ is equal to 0 ,

- $h_{w, t o t}$ is higher than 0 and $h_{w, s p r}$ is higher than 0 ,

- or $h_{w, t o t}$ is higher than 0 but $h_{w, s p r}$ is equal to 0 .

In the first case, the surface is dry then the conductive flux is simply defined as the difference between the global radiation flux and the sensible heat flux. In the second case, water is sprinkled on the surface. We assume that no evaporation occurs at this time step. The energy is exchanged between the water and the ground. This convective heat flux is calculated considering that the additional height of water $h_{w, s p r}$ reaches directly the surface temperature. Then a proportion of the total water height runs off decreasing the height of the water layer. The height $h_{w, c a p}$ of the water layer that remains at the surface depends on the water-holding capacity of the pavement. In the third case, the sprinklers are off some water remains on the surface. 
275 Only evaporation occurs and its potential is estimated and converted into 276 an equivalent water height $h_{\text {evap,th}}$. If $h_{w, t o t}$ is higher than $h_{\text {evap,th}}$, the latent 277 heat flux is equal to the evaporation potential. The remaining height $h_{w, t o t}$ 278 is converted to an equivalent latent heat flux. The water height decrease is 279 equal to the evaporated water height. Then the next time step is considered. 


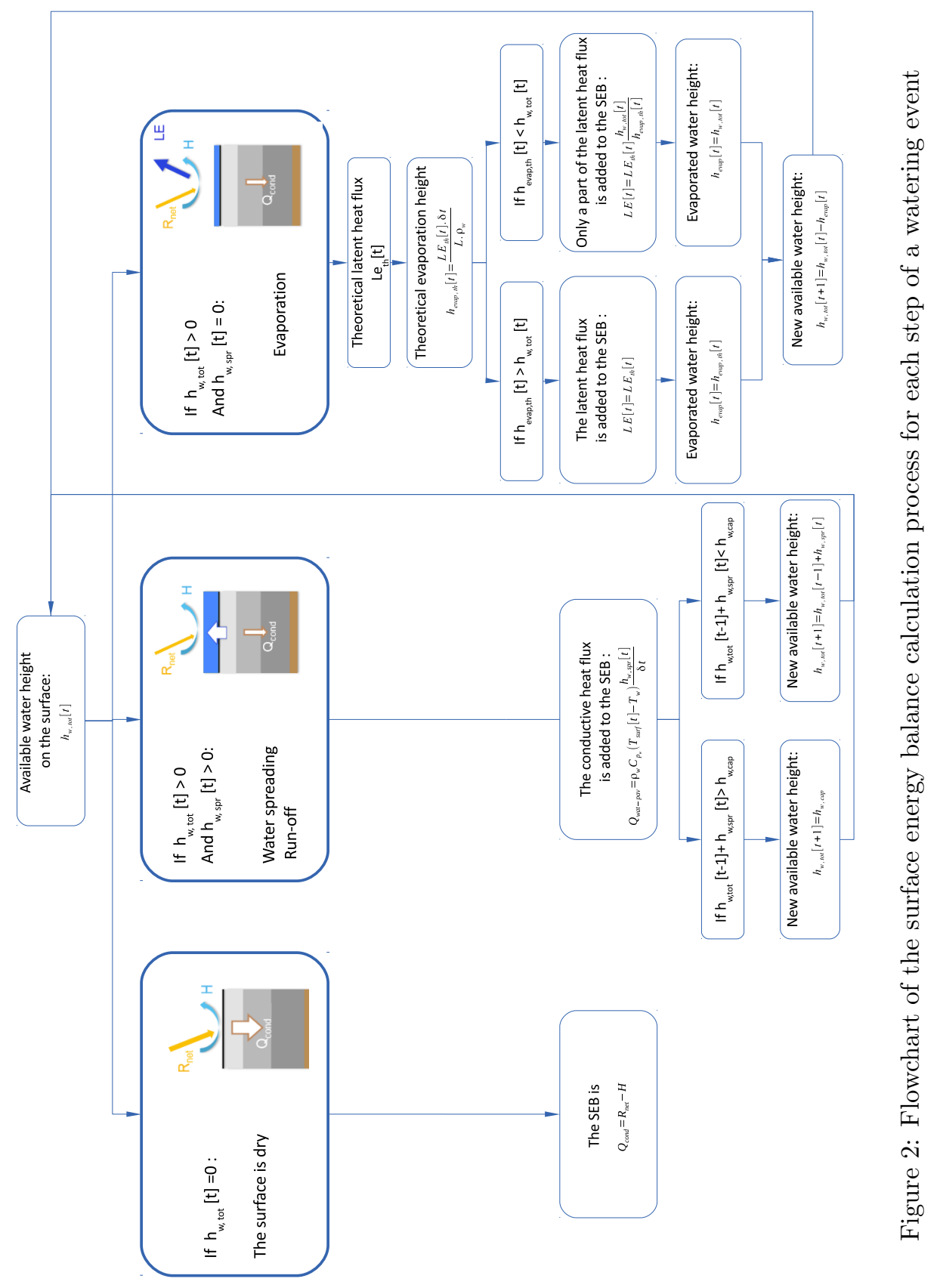




\section{Model assessment}

The model is evaluated on an open asphalt parking lot. The experiment and the analysis of the watering event are presented in section 3.1. Then the model will be applied to this case and assessed (section 3.2).

\subsection{Case study}

\subsubsection{Studied area and measurement description}

Data from the ROSURE/HydroVille experiment (Cohard et al., 2017 [28]) are used to calibrate and evaluate the pavement watering model. The experiment site is located near Nantes (France) and consisted of an asphalt car park of $2500 \mathrm{~m}^{2}$. This experiment focused on surface and air temperatures and on heat flux measurement during a warm summer period (June 2004). The car park was watered by means of a set of artificial rain events (Figure 3).

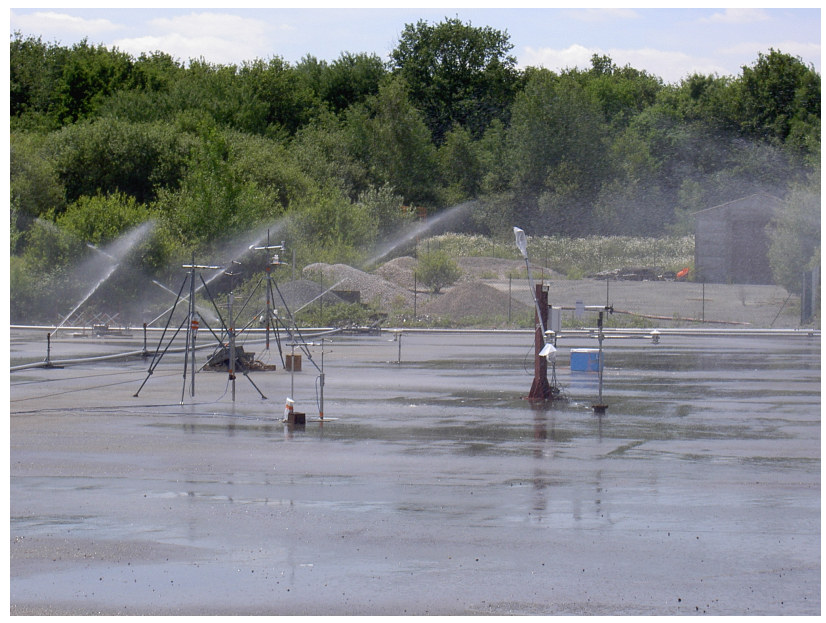

Figure 3: View of the experimental site during a watering event (an asphalt parking lot of $2500 \mathrm{~m}^{2}$ ) 
This study focused on the following variables, all observed in the car park:

- surface and ground temperature: vertical profile at $0,1,2,3,4,5,6$, $10,15,24,34,50$ and $75 \mathrm{~cm}$ depth;

- wind speed and direction;

- convective heat flux;

- latent heat flux;

- radiation components.

The humidity and air temperature were measured outside from the car park. The experimental devices are presented in Figure 4. The data were collected with a 1 min time step except for the sonic anemometer and the KH20 Campbell Sci whose time step were $0.1 \mathrm{~s}$. The final data were averaged to 15 min time step.

\subsubsection{Description of the watering events}

16 watering events (including one natural event - the $15^{\text {th }}$ ) were recorded during the entire measurement period (Figure 3). Each of them is described in table 1. During the events numbered 1,2,3 and 6, some technical issues occurred and the total volume of water may be different from what is presented in Table 1. For each event, several parameters have been measured:

- inlet: water temperature, flow, and volume,

- outlet water temperature, flow, and volume, - duration of each watering.

An indication is given on the approximate duration of the drying periods. 


\begin{tabular}{llllll} 
Watering & Date & Time & Total vol. of water & Intensity & Flow \\
Number & DD/MM/YY HH:MM & minutes & $m^{3}$ & $m m / m^{2}$ & $m^{3} / h$ \\
\hline $1 *$ & $02 / 06 / 0413: 42$ & 20 & 16.96 & 6.78 & 43 \\
$2 *$ & $03 / 06 / 0409: 53$ & 20 & 13.08 & 5.32 & 43 \\
$3 *$ & $03 / 06 / 0415: 04$ & 20 & 15.05 & 6.02 & 44 \\
4 & $04 / 06 / 0408: 49$ & 3 & 2.04 & 0.81 & 44 \\
5 & $04 / 06 / 0411: 57$ & 1.5 & 1.12 & 0.45 & 44 \\
$6 *$ & $04 / 06 / 0413: 57$ & 17 & 14.92 & 5.97 & 44 \\
7 & $07 / 06 / 0408: 51$ & 20 & 13.75 & 5.50 & 42 \\
8 & $07 / 06 / 0413: 43$ & 30 & 21.33 & 8.53 & 44 \\
9 & $08 / 06 / 0409: 45$ & 19 & 12.40 & 4.96 & 44 \\
10 & $08 / 06 / 0415: 04$ & 5 & 3.06 & 1.22 & 38 \\
11 & $09 / 06 / 0409: 25$ & 20 & 14.10 & 5.64 & 42 \\
12 & $09 / 06 / 0413: 40$ & 20 & 16.25 & 6.50 & 46 \\
13 & $09 / 06 / 0415: 38$ & 2 & 1.60 & 0.64 & 48 \\
14 & $10 / 06 / 0408: 30$ & 20 & 15.44 & 6.18 & 45 \\
15 & $10 / 06 / 0412: 25$ & 28 & 2.95 & 1.18 & - \\
16 & $11 / 06 / 0408: 40$ & 2 & 1.66 & 0.67 & 43 \\
\hline
\end{tabular}

Table 1: Description of each watering event 


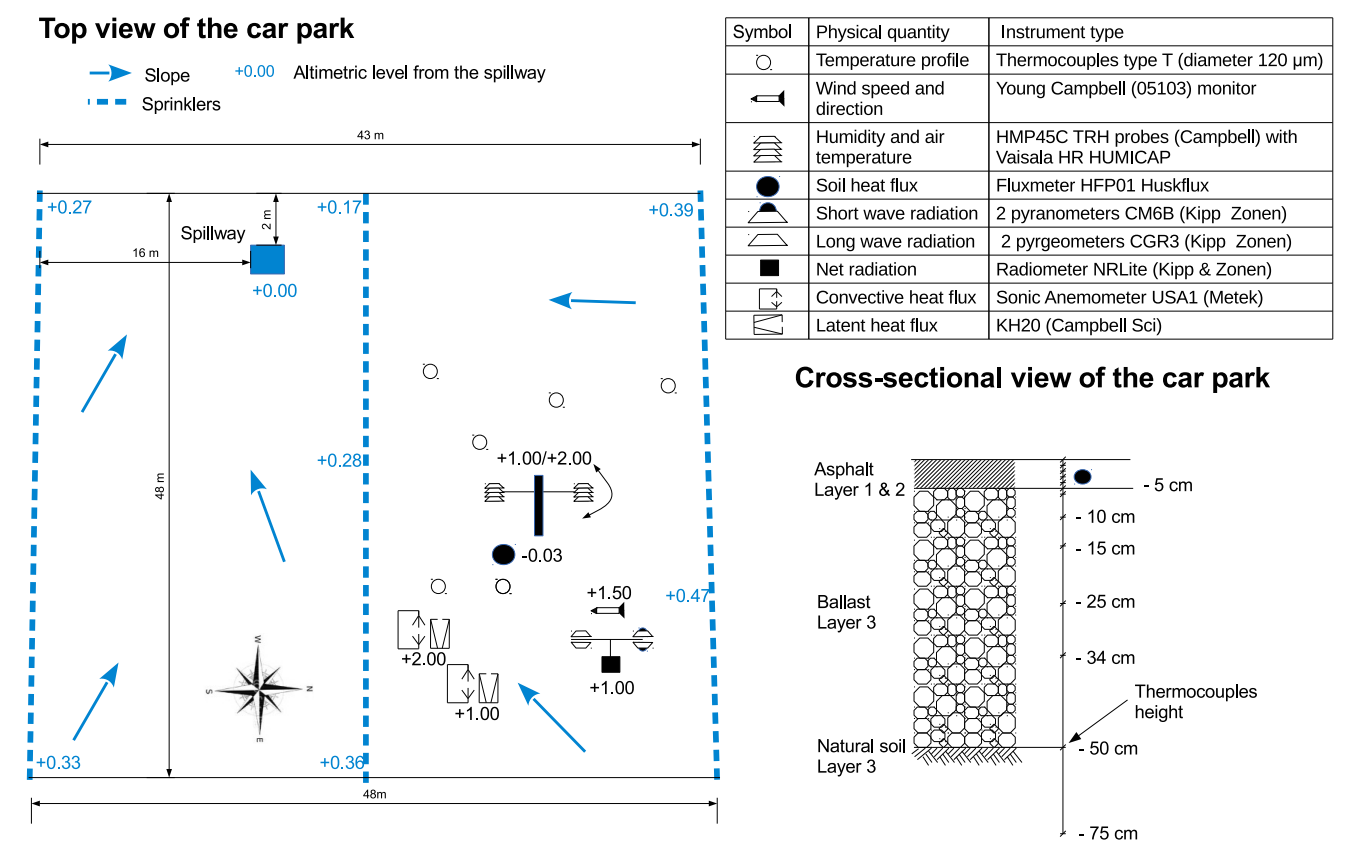

Figure 4: Top view of the car park with instruments approximate location during the campaign and cross-section of the soil composition (see Table 3 for the material properties)

\subsubsection{Validation of the model assumptions}

It is assumed (sections 2.2.2 and 2.2.4) that energy is exchanged between the runoff water and the surface only during the first time step ( $\mathrm{t}=15$ minutes). Then the latent heat flux is modelled. Those assumptions are here verified analysing the temperatures and heat flux measurements.

The surface temperature evolution is compared to the water temperature and flow in the spillway in Figure 5. As soon as the watering event begins (black line on Figure 5), the surface temperature drops and the water temperature increases (zone 1 on Figure 5) until they reach a balance (dashed line on Figure 5). A delay of several minutes can be observed between the temperature signals and the water flow signals (zones 1 and 3 on Figure 5). 


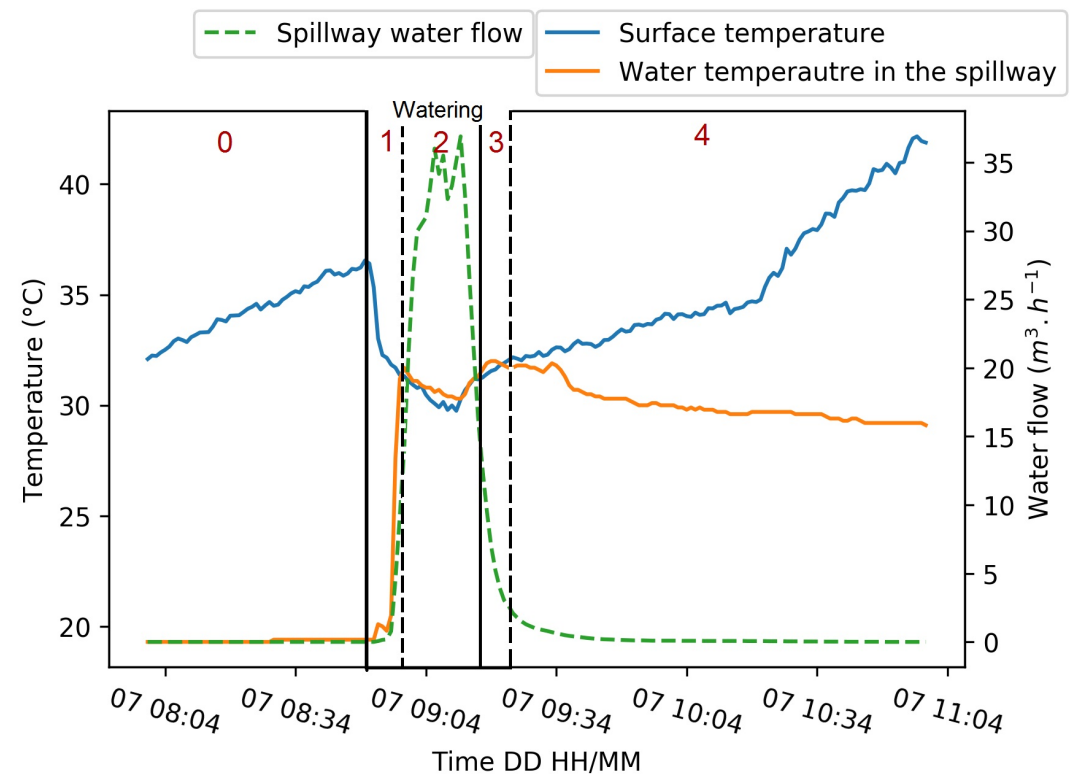

Figure 5: Watering event number 7, June $07^{t} h$ at 08:51am, measured surface temperature in the centre of the parking lot and measured water temperature and water flow in the spillway

The thermocouples are located at several meters from the spillway, as it can be observed in Figure 3. The delay between the different signals is consistent with the water travel time between the thermocouples location and the spillway. As the balance is reached, both temperatures increase (zone 3): no more energy is exchanged between the surface and the water layer. The thermocouples now measures the temperature of the standing water in the spillway, which slowly decreases (zone 4 on Figure 5).

Those observations are compared to the heat fluxes measured presented in Figure 6. As said before the water temperature reaches very quickly (less than 20 minutes) the surface temperature (Figure 5) whereas the conductive heat flux in the ground has a decreasing peak right after watering which then 


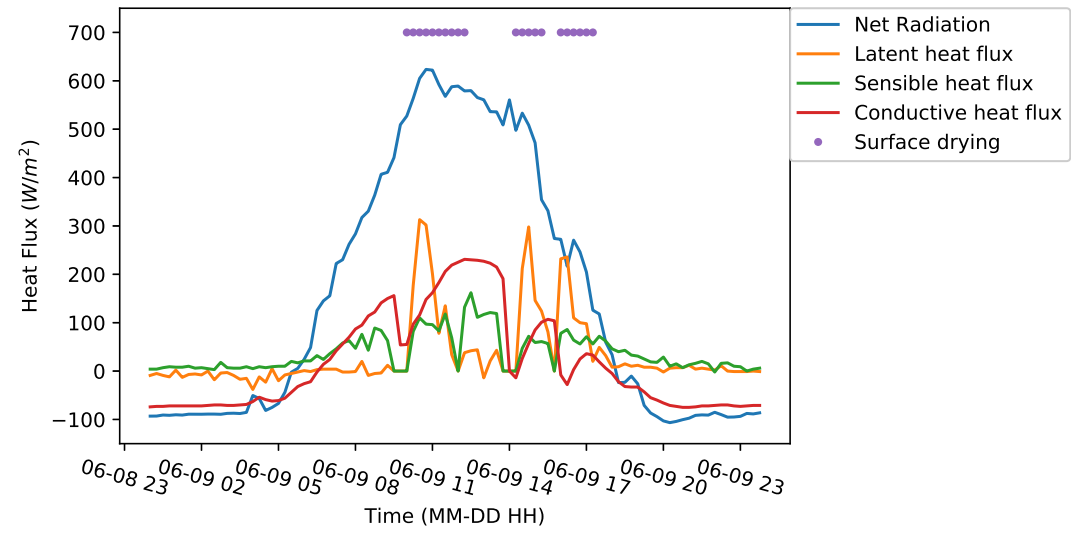

Figure 6: Observed surface energy balance (June $07^{\text {th }}$ )

shrink in a short time (about one hour) (Figure 6). Cohard et al (2017 [28]) also noticed a similar trend: the heat flux transferred from the ground to the water reaches $438 \mathrm{~W} / \mathrm{m}^{2}$ during a watering event and decreases as soon as the sprinklers stop (15 minutes). Those observations are consistent with the assumptions made for our modelling as well as the one used by Herb et al. (2008 [19]): the runoff convective heat flux exchanged between the water and the surface can be attributed to the first time step of the watering event. We assumed that air was saturated during the watering process and no evaporation occurred immediately. This assumption could not be verified in this experiment since the latent heat flux sensor was protected when the sprinklers were working.

\subsubsection{Water budget}

When some water is spread over a surface, a fraction runs off whereas the other fraction is intercepted by the surface until evaporation or infiltration. The distribution of runoff and pavement storage depends on the surface 
water-holding capacity, itself related to the surface roughness. This characteristic is a parameter of the model that should be set by the user. The purpose of this part is to estimate this parameter through the measurements of the water budget.

Cohard et al. (2017 [28]) estimated that for each watering event, the height of water infiltrating the ground does not exceed $0.2 \mathrm{~mm}$. The water left over the surface is thus considered as entirely evaporated. To calculate the corresponding amount, they tested several methods derived from latent heat flux measurement or estimation. Their conclusion is that the latent heat flux estimated according to the SEB method (using measurements for the other fluxes values) was the most accurate. The results fitted with the water budget contrary to the other method used. They were then able to evaluate for each watering event the amount of water evaporated. For events with high volume of water (more than $2 \mathrm{~mm}$ ), the mean evaporated height is $0.7 \mathrm{~mm}$. This value will be used as reference data for the evaluation of the model, and the water holding capacity will be calibrated in the model (see section 3.2.1).

\subsection{Comparison between simulation and measurement}

The model ability to properly reproduce the physical processes involved during a watering event is evaluated in this section. The model setup used are presented, then the model is evaluated at several depths. Finally, as the soil model is proposed for different optimised grid distributions, the model sensitivity to the node distribution is studied. 


\begin{tabular}{ll} 
Surface energy balance heat flux & Input data used to calculate each flux \\
\hline Convective heat flux & $\begin{array}{l}\text { wind speed } \\
\text { air temperature* }\end{array}$ \\
\hline Net radiative heat flux & Net radiative flux \\
\hline Latent heat flux & water height \\
& water-holding capacity of the surface \\
& air relative humidity* \\
& air temperature* \\
\hline Runoff convective heat flux & water temperature \\
& total sprinkled water for each event \\
\hline
\end{tabular}

*measured outside from the watered zone of the car park

Table 2: Detail of each input data necessary to calculate the upper boundary condition.

\subsubsection{Model setup}

The simulation is run for the whole period from June $5^{t h}$, 00:00 to June $14^{\text {th }}$, 00:00, with a time step of 15 minutes. For the soil thermal model, a centimetric grid is used.

\section{Surface energy balance:}

The heat fluxes are calculated from the observed data presented in Table 2. The convective heat flux is calculated from the air temperature and the wind speed. Radiative heat fluxes are the observations. The latent and runoff convective heat fluxes are calculated according to the processing chain presented in Figure 2. The runoff convective heat flux is calculated using the amount of water sprinkled during each watering event derived from the measurement. The temperature of the sprinkled water is set at $18{ }^{\circ} \mathrm{C}$ before it reaches the ground. The latent heat flux is calculated from the air characteristics measured outside from the watered zone. 


\section{Thermal characteristics:}

The soil is composed of three different materials: $5 \mathrm{~cm}$-of asphalt, $45 \mathrm{~cm}$ of ballast and an altered mica-schist natural soil underneath. Soil composition and thermal properties have not been measured during the experiment. They have been calibrated according to the observed soil thermal profile, reducing the difference between the measured and simulated surface temperature, with a centimetric-grid. Data acquired on the $6^{\text {th }}$ of June is used for calibration. From the measured temperature gradient, changes in the soil thermal properties within the first layer were identified $(0-1 \mathrm{~cm}, 1-5 \mathrm{~cm})$. Values are gathered in Table 3.

\begin{tabular}{|c|c|c|c|c|}
\hline Layer & Material & Depth & $\begin{array}{l}\text { Thermal conduc- } \\
\text { tivity }\end{array}$ & $\begin{array}{l}\text { Volumetric heat ca- } \\
\text { pacity }\end{array}$ \\
\hline Number & Characteristics & $\mathrm{m}$ & $W \cdot m^{-1} \cdot K^{-1}$ & $10^{6} \mathrm{~J} \cdot \mathrm{m}^{-3} \cdot K^{-1}$ \\
\hline 0 & Asphalt Concrete & 0.01 & 2.5 & 2.3 \\
\hline 1 & Asphalt Concrete & 0.05 & 2.5 & 2.1 \\
\hline 2 & Old Filled Ballast & 0.5 & 1.8 & 2.3 \\
\hline 3 & $\begin{array}{l}\text { Altered Mica-schist Natural } \\
\text { Soil }\end{array}$ & 1 & 1.3 & 2.1 \\
\hline
\end{tabular}

Table 3: Calibrated characteristics of the soil

\section{Water-holding capacity:}

The water storage capacity of the surface may vary a lot depending on the surface type. To better evaluate this value for our studied area, the model has been run for two days from the $7^{\text {th }}$ to the $8^{\text {th }}$ of June (4 watering events), testing the water storage height from 0.3 to 1.4. The effect on the 


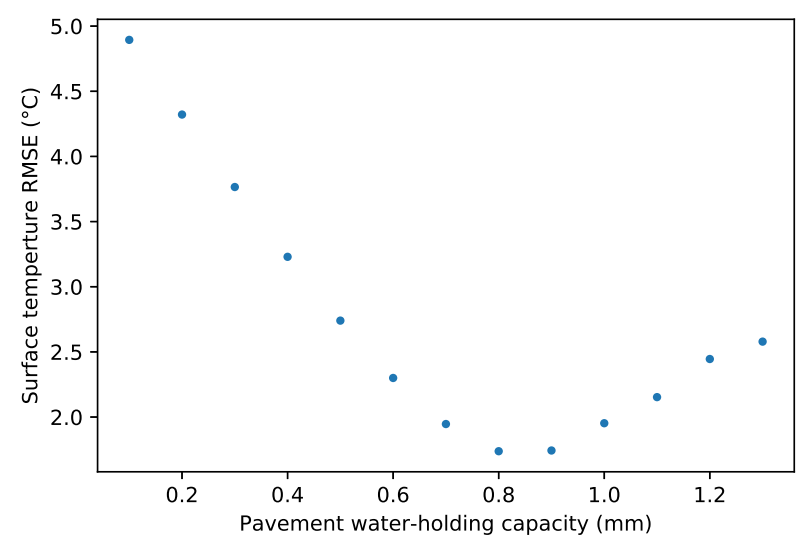

Figure 7: Surface temperature root-mean-square-error (RMSE) as a function of the pavement water-holding capacity $(\mathrm{mm})$ for the calibration period (June, $7^{\text {th }}$, and $8^{\text {th }}$ )

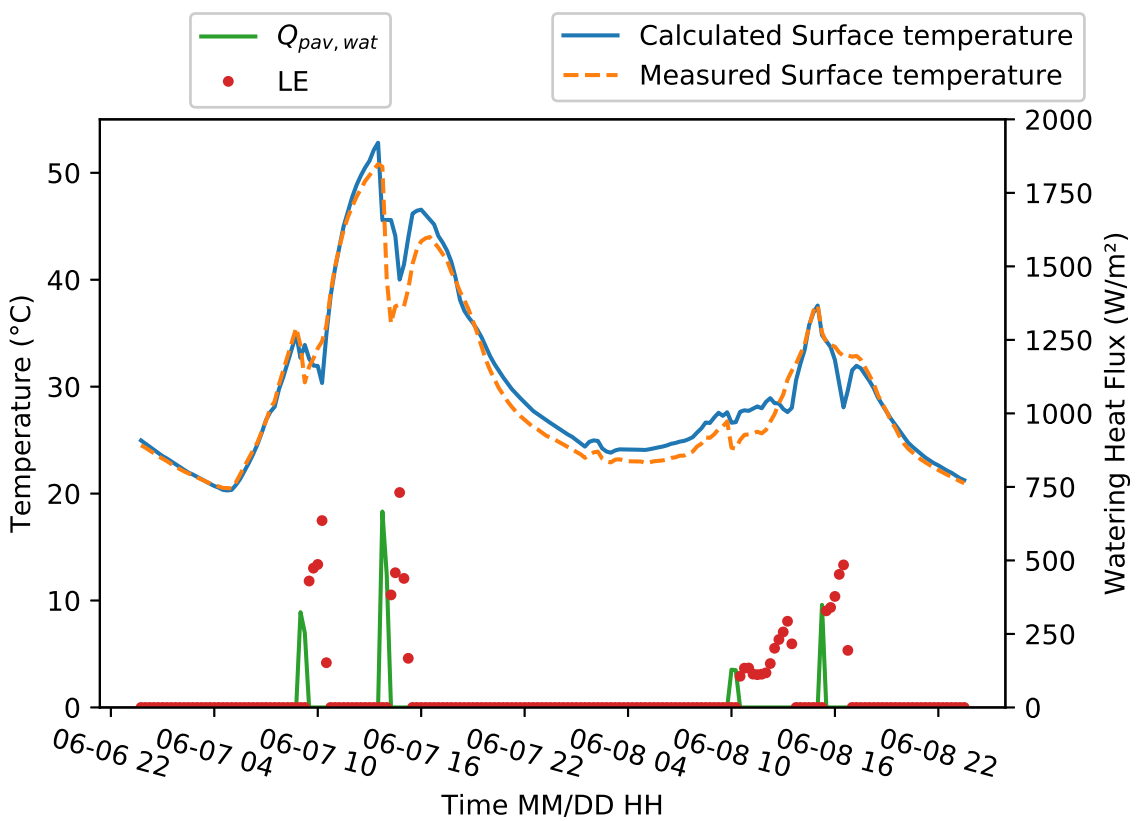

Figure 8: Comparison of simulated and measured temperatures at the surface for the calibration period (June, $7^{\text {th }}$, and $8^{\text {th }}$ ) 
surface temperature RMSE is shown in Figure 7. A water holding capacity of $0.8 \mathrm{~mm}$ minimises the surface temperature RMSE and then is used for the studied car park surface. Figure 8 presents the results of the calibration period and a minimum for a height of $0.8 \mathrm{~mm}$. The temporal variations are well reproduced (there is no phase lag between the signals) except during the watering events.

This value is consistent with the mean evaporated height calculated from SEB method for a high amount of water $(0.7 \mathrm{~mm})$. In the literature Hendel et al. (2015 [10]) estimate to $1 \mathrm{~mm}$ the water holding capacity of road surface in the centre of Paris. In TEB the default value is also set to $1 \mathrm{~mm}$ (Daniel et al., $2016[8])$.

\subsubsection{Watering model evaluation on ROSURE data}

The model evaluation is performed by comparing the time series of observed and modelled surface temperatures (Figure 9). Temporal variations of the surface temperature are well reproduced (there is no phase lag between the signals) except during the watering events. The same shape is obtained (a decreasing peak followed by more steady period and then an increasing peak) but a lag is observed. This lag might have been attributed to the assumption that the drying stage does not start as long as the sprinklers are in operation. To verify this assumption, we have run some simulations starting the evaporation stage while sprinklers were still working. The same time lag was noted and the simulated surface temperature was lower than the observed one or the initial simulation. This lag error could be attributed to the relative humidity measurement used for the latent heat flux calculation. The sensor is 


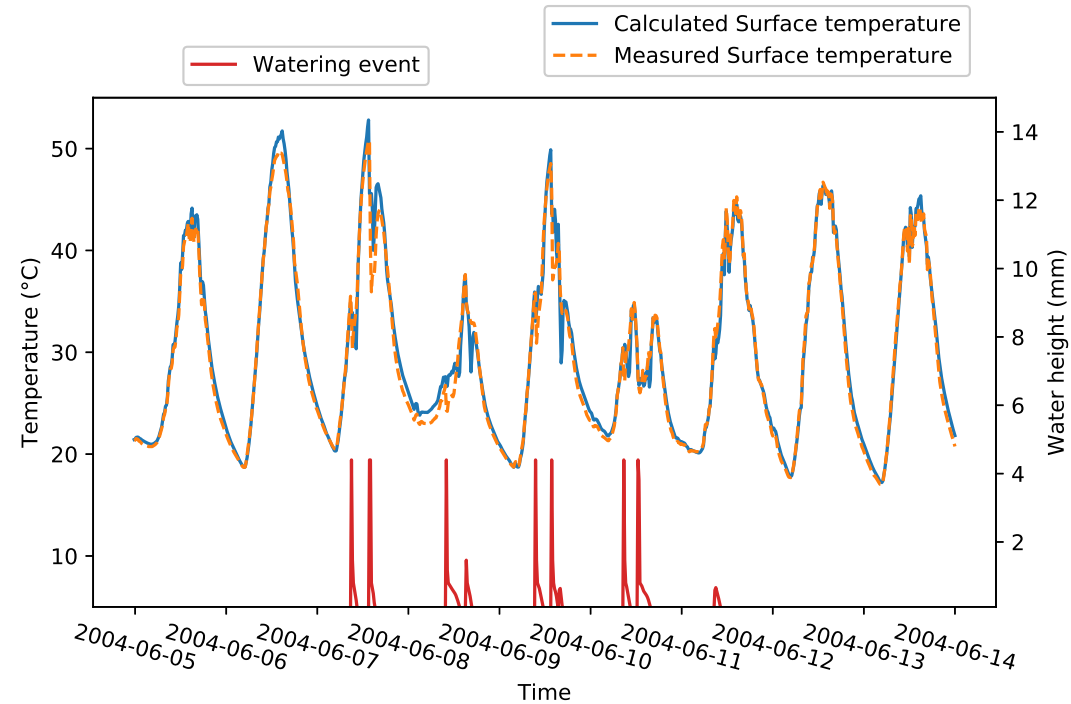

Figure 9: Comparison of simulated and measured temperatures at the surface from June, $5^{\text {th }}$, to $13^{\text {th }}$

located outside from the sprinkled area and thus potentially underestimates the real relative humidity of the air in the watered area. This results in an overestimation of the latent heat flux which may affect the dynamic of the surface energy balance.

In order to determine the overall model performance, the RMSE between estimated and observed temperatures is calculated at the surface and at several depths. To estimate the error which may be attributed only to the watering model, the RMSE is calculated for two different periods. The first period includes the entire campaign without the calibration days (from June $9^{\text {th }}$ to June $13^{\text {th }}$ ), whereas the second includes only two dry days (June $12^{\text {th }}$ and $13^{\text {th }}$ ). The first column assesses the overall model performance (soil and watering models) while the second indicates the performance relative 


\begin{tabular}{lll} 
Depth & RMSE $\left({ }^{\circ} \mathrm{C}\right)$ & RMSE $\left({ }^{\circ} \mathrm{C}\right)$ \\
& $\begin{array}{l}\text { From June } 8^{\text {th }} 23: 45 \text { to the } \\
13^{\text {th }} 23: 45 \\
\end{array}$ (soil + watering model) & $\begin{array}{l}\text { From June } 11^{\text {th }} 23: 45 \text { and } 13^{\text {th }} \\
\text { (soil model only) }\end{array}$ \\
\hline Surface & 1.04 & 0.71 \\
$5 \mathrm{~cm}$ & 0.86 & 0.93 \\
$10 \mathrm{~cm}$ & 0.66 & 0.78 \\
$34 \mathrm{~cm}$ & 0.35 & 0.46 \\
$50 \mathrm{~cm}$ & 0.21 & 0.29
\end{tabular}

Table 4: Evaluation of the centimetric grid watering model according to the experimental data

to the soil model only (ability to reproduce heat transfers into the ground). Results are presented in Table 4. The RMSE for the surface temperature is larger when watering events are simulated $\left(1.04^{\circ} \mathrm{C}\right)$ than when only the soil model is needed $\left(0.71^{\circ} \mathrm{C}\right)$. For this specific data set, the watering model increased the soil model error of $46 \%$. As the simulated days are not similar (weather condition are varying), this value is only representative for this specific simulation.

The assumption was made that the water-holding capacity of the surface was $0.8 \mathrm{~mm}$. As it is an important parameter, the model is also evaluated on its ability to calculate the latent heat flux. For each event, the latent heat fluxes calculated by the model and estimated from the SEB residual method are integrated over each event. The total energy due to evaporation for both methods is compared in Table 5. The relative error stays below $29 \%$. On average, the model overestimates the latent heat flux by $12 \%$.

The air temperature and the relative humidity used to calculate the evap- 


\begin{tabular}{|c|c|c|c|c|c|c|}
\hline Watering & Date & Duration & $\begin{array}{l}\text { Total height } \\
\text { of the water } \\
\text { layer spread }\end{array}$ & $\begin{array}{l}\text { Latent heat } \\
\text { measured } \\
\text { from SEB } \\
\text { method }\end{array}$ & $\begin{array}{l}\text { Latent heat } \\
\text { calculated by } \\
\text { the model }\end{array}$ & Relative error \\
\hline Number & DD/MM/YY HH:MM & minutes & $\mathrm{mm}$ & $10^{6} \mathrm{~J}$ & $10^{6} \mathrm{~J}$ & $\%$ \\
\hline 7 & 07/06/04 08:51 & 20 & 5.50 & 2.11 & 1.96 & -7.17 \\
\hline 8 & 07/06/04 13:43 & 30 & 8.53 & 2.36 & 1.96 & -17.04 \\
\hline 9 & 08/06/04 09:45 & 19 & 4.96 & 2.00 & 1.96 & -2.12 \\
\hline 10 & 08/06/04 15:04 & 5 & 1.22 & 1.52 & 1.96 & 28.71 \\
\hline 11 & 09/06/04 09:25 & 20 & 5.64 & 1.52 & 1.96 & 28.79 \\
\hline 12 & 09/06/04 13:40 & 20 & 6.50 & 1.42 & 1.76 & 23.77 \\
\hline 13 & 09/06/04 15:38 & 2 & 0.64 & 1.30 & 1.57 & 21.07 \\
\hline 14 & 10/06/04 08:30 & 20 & 6.18 & 1.72 & 1.96 & 13.66 \\
\hline 15 & 10/06/04 12:25 & 28 & 1.18 & 1.74 & 1.96 & 12.60 \\
\hline 16 & $11 / 06 / 0408: 40$ & 2 & 0.66 & 1.32 & 1.63 & 22.88 \\
\hline
\end{tabular}

Table 5: Comparison of the latent heat flux estimated from SEB residue and calculated by the model. For each event, the latent heat fluxes are summed over the event duration.

oration were measured outside from the car park. If local parameters were used, an increase of the relative humidity and a decrease of the air temperature would have been observed. Then the calculated evaporation heat flux would have been smaller. The use of non-local meteorological data overestimates the latent heat flux calculation.

\subsubsection{Model sensitivity to the discretization}

In order to reduce the simulation duration while keeping a reasonable accuracy, three node distributions for the soil layer have been proposed in Azam et al. (2017 [17]). They are presented in Figure 10. The sensitivity of the model to the node distribution is here evaluated.

Figure 11 compares the surface temperature modelled with the three dif- 


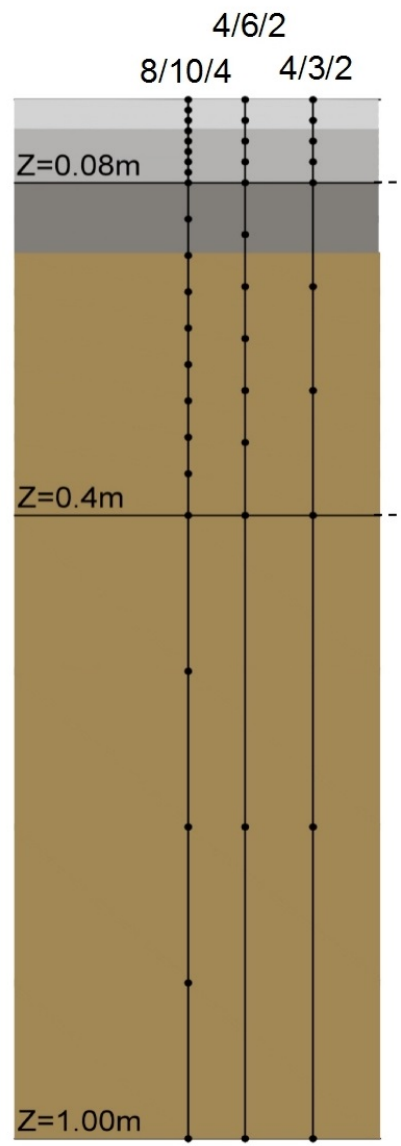

Figure 10: Description of the different grids

ferent node distributions with the measured one. Firstly, the three node distributions allow an accurate modelling of the time series of surface temperature. Nevertheless, the daily maximum peak and minimum trough are underestimated.

The underestimated daily maximum peak and minimum trough are due to the heat fluxes implementation during watering events. However, the reduction in the number of nodes deteriorates the results as it leads to dete- 


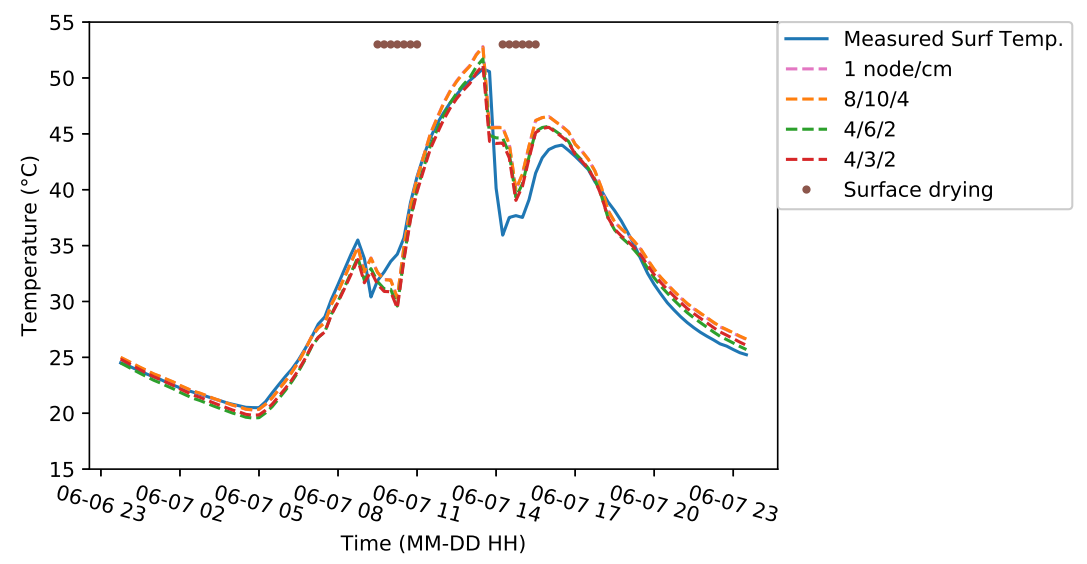

Figure 11: Surface temperature calculated with the different grids compared to that measured (June $7^{\text {th }}$ )

riorate the representation of the heat transfer into the ground. In fact, this induces a time shift of heat conduction, the main influence of which appears when its sign changes.

The RMSE between simulated and observed surface temperatures is calculated for each node distribution (Table 6). The accuracy loss due to the reduction of the number of nodes is also evaluated calculating the RMSE of

\begin{tabular}{|c|c|c|c|c|c|}
\hline Date & $\begin{array}{l}\text { Reference data for RMSE } \\
\text { calculation }\end{array}$ & centimetric grid & $\operatorname{grid} 8 / 10 / 4$ & $\operatorname{grid} 4 / 6 / 2$ & $\operatorname{grid} 4 / 3 / 2$ \\
\hline $\begin{array}{l}\text { From June } 8^{\text {th }} 23: 45 \text { to the } \\
13^{\text {th }} 23: 45\end{array}$ & observed temperature $\left({ }^{\circ} \mathrm{C}\right)$ & 1.04 & 1.04 & 1.44 & 1.50 \\
\hline$($ soil + watering model $)$ & $\begin{array}{l}\text { simulated temperature using } \\
\text { centimetric grid }\left({ }^{\circ} \mathrm{C}\right)\end{array}$ & - & 0.02 & 1.18 & 1.21 \\
\hline June $12^{t h}$ and $13^{t h}$ & observed temperature $\left({ }^{\circ} \mathrm{C}\right)$ & 0.70 & 0.72 & 1.10 & 1.20 \\
\hline (soil model only) & $\begin{array}{l}\text { simulated temperature using } \\
\text { centimetric grid }\left({ }^{\circ} \mathrm{C}\right)\end{array}$ & - & 0.03 & 1.14 & 1.15 \\
\hline
\end{tabular}

Table 6: Evaluation of the model with a reduced number of nodes 
the simulated surface temperature between each node distribution and the centimetric grid (1 node per $\mathrm{cm}$ ). The $8 / 10 / 4$ grid has almost no effect on the simulation performances (the RMSE increase is lower than $4 \%$ ). The absolute RMSE increase due to the node distribution is almost similar regardless the models used (soil model only or soil model + watering model): $0.02,1.18$, and $1.21^{\circ} \mathrm{C}$ for grids $8 / 10 / 4,4 / 6 / 2$ and $4 / 3 / 2$, respectively. If we report these RMSE to the one due to the model itself (centimetric grid relative to the observed data), the relative accuracy loss due to the nodes distribution is much lower when the water model is taken into consideration.

\section{Conclusion}

This article focuses on pavement watering as a possible mitigation technique of the UHI effect under heat waves conditions. The literature review revealed that this technique has been mainly studied through experimental works. To the best of our knowledge, the impact of pavement watering on urban energy balance at the micro-scale has not yet been addressed by modelling.

The main purpose of this article was to implement a watering model within an urban micro-scale model (SOLENE-Microclimat) and to evaluate it according to a field experiment.

The watering model was elaborated on a literature review and evaluated on an open asphalt car park. Two fluxes were taken into account: the runoff convective heat flux (exchanged between the surface and the runoff water) and the latent heat flux. The runoff convective heat flux is often neglected 
by existing models at meso-scale whereas the high difference of temperature between surface and the water spread makes it prevailing under heat wave conditions. In the case of the experiment used to evaluate the model, the modelled heat flux represents $20 \%$ of the overall cooling flux $\left(Q_{\text {wat-pav }}+\mathrm{LE}\right)$ due to the pavement watering.

The latent heat flux is limited by the water holding capacity of the pavement. This important parameter has been estimated using two methods: one based on simulation and the other based on the observation. The results are almost similar: the water holding capacity of the studied pavement is about $0.8 \mathrm{~mm}$, comparable to the $1 \mathrm{~mm}$ height found in the literature. The estimated latent heat flux is in average $12 \%$ higher than the observed one. The relative error never exceeds $30 \%$. An explanation of this overestimation is that the relative humidity data used for the latent heat flux calculation was probably lower than the reality (the sensor was located outside the watered area).

The global accuracy of the model was evaluated using the temperature observed at the surface and at several depths. The absolute RMSE for the surface temperature is larger when watering events are simulated $\left(1.04{ }^{\circ} \mathrm{C}\right)$ than under dry conditions when only the soil model is used $\left(0.71^{\circ} \mathrm{C}\right)$.

The sensitivity of the model to the node distribution has finally been studied. Three soil model node distributions were compared. The 8/10/4 grid has almost no effect on the simulation performances (the RMSE increase is lower than $4 \%$ ). 
This paper provides a detail evaluation of the watering model performances when compared with experimental data. This model can be used to assess the cooling induced by pavement watering mitigation technique at micro-scale, which was not possible until now. The impact on local comfort could then be estimated.

The efficiency of watering techniques is constrained by the surface potential evaporation which depends directly on the surface holding capacity. The model could then be used to optimise the watering scenario according to the surface characteristics of streets. The impact of different materials on microclimat model could then be compared.

\section{Acknowledgements}

This research work was carried out within the scope of the EVA Project, funded by the ADEME (French Environment and Energy Management Agency) under contract no. $1216 C 0037$ and conducted in collaboration with Veolia 2EI. The authors are grateful to the ADEME for its financial support, as well as to IFSTTAR, LHEEA, and ONEVU for providing us with the experimental data.

\section{References}

[1] J.-M. Robine, S. L. K. Cheung, S. Le Roy, H. Van Oyen, C. Griffiths, J.P. Michel, F. R. Herrmann, Death toll exceeded 70,000 in europe during the summer of 2003, Comptes rendus biologies 331 (2008) 171-178. 
[2] K. Laaidi, A. Zeghnoun, B. Dousset, P. Bretin, S. Vandentorren, E. Giraudet, $\mathrm{P}$. Beaudeau, The impact of heat islands on mortality in paris during the august 2003 heat wave, Environmental health perspectives 120 (2012) 254.

[3] S. Conti, P. Meli, G. Minelli, R. Solimini, V. Toccaceli, M. Vichi, C. Beltrano, L. Perini, Epidemiologic study of mortality during the summer 2003 heat wave in italy, Environmental research 98 (2005) 390-399.

[4] M. Santamouris, L. Ding, F. Fiorito, P. Oldfield, P. Osmond, R. Paolini, D. Prasad, A. Synnefa, Passive and active cooling for the outdoor built environment-analysis and assessment of the cooling potential of mitigation technologies using performance data from 220 large scale projects, Solar Energy (2016).

[5] M. A. Hendel, M. Colombert, Y. Diab, L. Royon, Measurement of the cooling efficiency of pavement-watering as an urban heat island mitigation technique, Journal of Sustainable Development of Energy, Water and Environment Systems 3 (2015) 1-11.

[6] S. Himeno, R. Takahashi, A. Asakura, K. Koike, S. Fujita, Using snow melting pipes to verify the water sprinkling s effect over a wide area, NOVATECH 2010 (2010).

[7] X. Yang, L. Zhao, Diurnal thermal behavior of pavements, vegetation, and water pond in a hot-humid city, Buildings 6 (2015) 2.

[8] M. Daniel, A. Lemonsu, V. Viguié, Role of watering practices in large- 
scale urban planning strategies to face the heat-wave risk in future climate, Urban Climate (2016).

[9] A. M. Broadbent, A. M. Coutts, N. J. Tapper, M. Demuzere, The cooling effect of irrigation on urban microclimate during heatwave conditions, Urban Climate (2017).

[10] M. Hendel, M. Colombert, Y. Diab, L. Royon, An analysis of pavement heat flux to optimize the water efficiency of a pavement-watering method, Applied Thermal Engineering 78 (2015) 658-669.

[11] S. Grossman-Clarke, J. A. Zehnder, T. Loridan, C. S. B. Grimmond, Contribution of land use changes to near-surface air temperatures during recent summer extreme heat events in the phoenix metropolitan area, Journal of Applied Meteorology and Climatology 49 (2010) 1649-1664.

[12] C. Grimmond, M. Blackett, M. Best, J. Barlow, J. Baik, S. Belcher, S. Bohnenstengel, I. Calmet, F. Chen, A. Dandou, et al., The international urban energy balance models comparison project: first results from phase 1, Journal of applied meteorology and climatology 49 (2010) $1268-1292$.

[13] V. Masson, A physically-based scheme for the urban energy budget in atmospheric models, Boundary-layer meteorology 94 (2000) 357-397.

[14] L. Malys, Évaluation des impacts directs et indirects des façades et des toitures végétales sur le comportement thermique des bâtiments, Ph.D. thesis, École nationale supérieure d'architecture (Nantes), 2012. 
[15] M. Musy, L. Malys, B. Morille, C. Inard, The use of solene-microclimat model to assess adaptation strategies at the district scale, Urban Climate 14 (2015) 213-223.

[16] J. Bouyer, Modelisation et simulation des microclimats urbains-Etude de l'impact de l'amenagement urbain sur les consommations energetiques des batiments, Ph.D. thesis, Universite de Nantes, 2009.

[17] M.-H. Azam, B. Morille, J. Bernard, M. Musy, F. Rodriguez, A new urban soil model for solene-microclimat: Review, sensitivity analysis and validation on a car park, Urban Climate (2017).

[18] S. Dupont, P. G. Mestayer, E. Guilloteau, E. Berthier, H. Andrieu, Parameterization of the urban water budget with the submesoscale soil model, Journal of Applied Meteorology and Climatology 45 (2006) 624648.

[19] W. R. Herb, B. Janke, O. Mohseni, H. G. Stefan, Ground surface temperature simulation for different land covers, Journal of Hydrology 356 (2008) 327-343.

[20] V. Singh, C. Xu, Evaluation and generalization of 13 mass-transfer equations for determining free water evaporation, Hydrological Processes 11 (1997) 311-323.

[21] C.-Y. Xu, V. Singh, Evaluation and generalization of temperature-based methods for calculating evaporation, Hydrological processes 15 (2001) $305-319$. 
[22] T. Asaeda, V. T. Ca, The subsurface transport of heat and moisture and its effect on the environment: a numerical model, Boundary-Layer Meteorology 65 (1993) 159-179.

[23] Z. Qin, P. Berliner, A. Karnieli, Numerical solution of a complete surface energy balance model for simulation of heat fluxes and surface temperature under bare soil environment, Applied mathematics and computation 130 (2002) 171-200.

[24] H. Saito, J. Simunek, Effects of meteorological models on the solution of the surface energy balance and soil temperature variations in bare soils, Journal of Hydrology 373 (2009) 545-561.

[25] M. Best, A model to predict surface temperatures, Boundary-Layer Meteorology 88 (1998) 279-306.

[26] G. Mihalakakou, M. Santamouris, J. Lewis, D. Asimakopoulos, On the application of the energy balance equation to predict ground temperature profiles, Solar Energy 60 (1997) 181-190.

[27] O. A. Alduchov, R. E. Eskridge, Improved magnus form approximation of saturation vapor pressure, Journal of Applied Meteorology 35 (1996) 601-609.

[28] J. Cohard, J. Rosant, F. Rodriguez, H. Andrieu, P. Mestayer, P. Guillevic, Energy and water budgets of asphalt concrete pavement under simulated rain events, Urban Climate (2017). 